\title{
Clustering of health-related behaviors, health outcomes and demographics in Dutch adolescents: a cross-sectional study
}

\author{
Vincent Busch", Henk F Van Stel, Augustinus JP Schrijvers and Johannes RJ de Leeuw
}

\begin{abstract}
Background: Recent studies show several health-related behaviors to cluster in adolescents. This has important implications for public health. Interrelated behaviors have been shown to be most effectively targeted by multimodal interventions addressing wider-ranging improvements in lifestyle instead of via separate interventions targeting individual behaviors. However, few previous studies have taken into account a broad, multi-disciplinary range of health-related behaviors and connected these behavioral patterns to health-related outcomes. This paper presents an analysis of the clustering of a broad range of health-related behaviors with relevant demographic factors and several health-related outcomes in adolescents.

Methods: Self-report questionnaire data were collected from a sample of 2,690 Dutch high school adolescents. Behavioral patterns were deducted via Principal Components Analysis. Subsequently a Two-Step Cluster Analysis was used to identify groups of adolescents with similar behavioral patterns and health-related outcomes.

Results: Four distinct behavioral patterns describe the analyzed individual behaviors: 1- risk-prone behavior, 2- bully behavior, 3- problematic screen time use, and 4- sedentary behavior. Subsequent cluster analysis identified four clusters of adolescents. Multi-problem behavior was associated with problematic physical and psychosocial health outcomes, as opposed to those exerting relatively few unhealthy behaviors. These associations were relatively independent of demographics such as ethnicity, gender and socio-economic status.

Conclusions: The results show that health-related behaviors tend to cluster, indicating that specific behavioral patterns underlie individual health behaviors. In addition, specific patterns of health-related behaviors were associated with specific health outcomes and demographic factors. In general, unhealthy behavior on account of multiple health-related behaviors was associated with both poor psychosocial and physical health. These findings have significant meaning for future public health programs, which should be more tailored with use of such knowledge on behavioral clustering via e.g. Transfer Learning.
\end{abstract}

\section{Background}

Health-related behaviors such as smoking, peer bullying, alcohol use and unhealthy nutritional habits contribute significantly to the public health burden of major, contemporary diseases such as diabetes, cardiovascular disease and psychiatric and psychosocial disorders. Many of such behaviors originate during adolescence and frequently lead to impaired adult health [1,2]. Recent studies show that several of such health-related behaviors

\footnotetext{
* Correspondence: v.busch@umcutrecht.nl

Julius Center for Health Sciences and Primary Care, University Medical Center Utrecht, Universiteitsweg 100, STR. 6.131, Postbus 85500, 3508 GA, Utrecht, The Netherlands
}

influence each other in a clustered fashion instead of acting independently on one's health [3-7]. Such clustering has important implications for research and practice due to the resulting synergistic effects, meaning that particular behaviors share a certain variance, resulting in the fact that changing one behavior affects prevalence of another [8,9]. Certain behaviors increase the likelihood of being involved in other risk behaviors [10], e.g. alcohol users are more likely to partake in smoking use than non-drinkers [9]. Such synergistic effects have been shown to increase disease risk to a level greater than either factor alone $[3-5,8,9]$. The underlying hypothesis behind this is that on top of the health risks that come from a certain behavior,

\section{Biomed Central}


one's mindset and decision-making processes are affected by partaking in a certain behavior [9].

This has important implications for preventive interventions, because "if there is covariance between these behaviors, then programs that fail to engage multiple risk behaviors are unlikely to be successful or to generate lasting effects" [11]. When behavior A and B cluster, then intervention on behavior A might affect behavior B, even though that was not directly targeted. Conversely, when behavior B is left out, intervening on behavior A might be less effective than a combined approach. Interventions that simultaneously tackled clustered health behaviors have been shown to be more effective as well as less costly $[6,10,12]$.

Such intervention tailoring requires knowledge on the clustering characteristics of a broad scope of health behaviors. However, most past studies on health behavioral clustering focused on a relative small range of health behaviors. They mostly focused on the clustering of nutrition, smoking and exercise $[8,13]$, while some additionally included alcohol use $[11,14]$, safe sex $[9,15]$ or sedentary time [16-18]. However, few studies thus far included behaviors such as bullying/being bullied and/or screen time use (watching TV, playing videogames, using the internet/PC), while their relevance to adolescent health has become increasingly evident [19-26]. Especially the "compulsive aspect" of screen time use has been overlooked thus far, while this is increasingly shown to affect both adolescents' physical and psychosocial health [19-22,27,28]. Therefore, a better understanding of the interrelations of a broad, comprehensive scope of health behaviors is needed [12]. In addition, despite evidence that several health-related behaviors can negatively affect one's physical and mental health, thus far studies have generally focused only on the associations of such clusters of health behaviors with physical health (mostly on overweight). The relations with psychosocial factors (e.g. self-efficacy or resilience) are underexposed, while they are often targets of health promoting interventions [29,30]. Also, only few studies have focused on adolescents as the population of interest, while they form such a unique population in which many health-related behavior habits find their origin $[1,2,31]$.

Therefore, this study aimed to identify clustering of a comprehensive number of health-related behaviors in adolescents, and, subsequently, to identify groups of adolescents with similar behavior and health outcomes.

\section{Methods}

\section{Sample and procedures}

Students from different educational levels, ethnic backgrounds and ages of five middle-large Dutch high schools (adolescents, 11-18 years old) received an online questionnaire in September 2012. These schools form a convenience sample with all schools participating out of intrinsic motivation, without being provided with funds or other incentives to participate. All schools were assisted with the questionnaire procedures by the research team. All schools are situated in suburban areas of middle to large cities in the Netherlands, are categorized as in-between rural and urban, and include students from both urban and rural background. Students completed the survey individually during class. Survey procedures were designed to allow students to participate voluntarily and anonymously. Students were made aware that all data were collected confidentially and stored under a password protected website, only to be assessed by the direct researchers and to be processed anonymously. Students and parents were informed on the nature and format of the survey in timely fashion and were made explicitly clear that participation was voluntary. Approximately $80 \%$ of the eligible students completed the survey. Only students with conflicting course schedules (according to their teachers) or those that were ill/absent on the day of the survey did not participate. Since the actual day and timing of the surveys was unannounced, selection bias was prevented in this step. This study has been approved by the Medical Ethics Committee of the University Medical Center Utrecht (UMCU), The Netherlands. METC-protocol number 11-397 / C. For this study the UMCU's Medical Ethics Committee decided no informed consent procedure was necessary, due to the coded data.

\section{Measures}

Data consisted of self-report data from a sample of Dutch high school adolescents on their relevant demographics, a range of health behaviors and several health outcomes. All outcomes concerned the individual students as the primary sampling unit of the study. The questionnaire was based on the Dutch version of the WHO's Health Behavior in School-Aged Children (HBSC) questionnaire [32,33]. Table 1 shows the operationalization of all main measures. All behaviors that were included regarded "Recent behaviors", meaning that one indicated to partake in a certain behavior in the month prior to filling out the questionnaire. With regard to bullying this concerned three months prior to filling in the survey. The questions regarding psychosocial problems and selfefficacy were more general, without indicating a certain period of time in which the behaviors had to have taken place.

The included health-related behaviors were alcohol use, drug use, smoking, physical exercise, nutrition, sexual behavior, screen time (watching television, (online) gaming and internet use) and peer bullying. Most items were surveyed in similar fashion to those of the Dutch HBSC questionnaire; these are summarized in Table 1. 
Table 1 The operationalization of the studied health behaviors and health indicators $(\mathrm{N}=2,690)$

\begin{tabular}{|c|c|c|}
\hline Variable & Item & Operationalization \\
\hline \multirow[t]{2}{*}{ Cannabis Use [32] } & Have you ever used Cannabis (hashish, marihuana or weed)? & 0) No, 1) Yes \\
\hline & $\begin{array}{l}\text { Have you recently (in the last } 4 \text { weeks) used cannabis (hashish, } \\
\text { marihuana or weed) }\end{array}$ & 0) No, 1) Yes \\
\hline \multirow[t]{4}{*}{ Alcohol use [32] } & Have you ever drunk alcohol? & 0) No, 1) Yes \\
\hline & Have you recently drunk alcohol? & 0) No, 1) Yes \\
\hline & How many days a week do you drink alcohol? & Number a day \\
\hline & How many glasses, cans or bottles of alcohol do you drink a day? & Number a day \\
\hline Binge drinking [32] & $\begin{array}{l}\text { How often in the last } 4 \text { weeks have you had more than } 4 \text { alcoholic } \\
\text { beverages on one occasion? }\end{array}$ & $\begin{array}{l}\text { Number of times, ranging from "Never" to "9 } \\
\text { Times or more". }\end{array}$ \\
\hline \multirow[t]{3}{*}{ Smoking [32] } & Have you ever smoked a cigarette? & 0) No, 1) Yes \\
\hline & Have you recently smoked a cigarette? & 0) No, 1) Yes \\
\hline & How many cigarettes do you smoke per week? & $\begin{array}{l}\text { Categories advancing with } 10 \text { pieces per } \\
\text { category, ranging from "0-10" to "70 or more" }\end{array}$ \\
\hline \multirow[t]{3}{*}{ Nutrition [32] } & How often do you have breakfast per week? & Number of days \\
\hline & How often do you eat vegetables per week? & Number of days \\
\hline & How often do you eat fruits per week? & Number of days \\
\hline \multirow{6}{*}{$\begin{array}{l}\text { Physical } \\
\text { exercise [32] }\end{array}$} & How do you travel to school usually? & 0) By bike, 1) Walking, 2) Else \\
\hline & How long does it take you to walk or bike to school (one-way trip)? & Number of mins \\
\hline & How many hours of gym class do you have at school each week? & Categories ranging from " 0 " to " 4 ". \\
\hline & Are you a member at a sports club? & 0) No, 1) Yes \\
\hline & How many hours a week do you spend at your sports club? & Number of hours \\
\hline & $\begin{array}{l}\text { How many hours a week do you spend on other sports related } \\
\text { activities than previously addressed? }\end{array}$ & Number of hours \\
\hline \multirow[t]{2}{*}{ Watching TV [32] } & How many days a week do you watch TV? & Number of days \\
\hline & How many hours a day do you watch TV? & $\begin{array}{l}\text { 0) Less than } 30 \text { mins, 1) } 30 \text { mins }-1 \text { hour, 2) } \\
1-2 \text { hours, 3) } 2-3 \text { hours, 4) }>3 \text { hours }\end{array}$ \\
\hline \multirow[t]{2}{*}{$\begin{array}{l}\text { Using the } \\
\text { internet/PC [32] }\end{array}$} & $\begin{array}{l}\text { How many days per week do you use the internet/PC } \\
\text { (not for school purposes)? }\end{array}$ & Number of days \\
\hline & $\begin{array}{l}\text { How many hours a day do you use the internet/PC (not for school } \\
\text { purposes) }\end{array}$ & $\begin{array}{l}\text { 0) Less than } 30 \text { mins, 1) } 30 \text { mins }-1 \text { hour, 2) } \\
\text { 1-2 hours, 3) } 2-3 \text { hours, 4) }>3 \text { hours }\end{array}$ \\
\hline \multirow{2}{*}{$\begin{array}{l}\text { Videogame } \\
\text { playing [32] }\end{array}$} & How many days a week do you play videogames on a game console? & Number of days \\
\hline & How many hours a day do you play videogames on a game console? & $\begin{array}{l}\text { 0) Less than } 30 \text { mins, 1) } 30 \text { mins }-1 \text { hour, 2) } \\
\text { 1-2 hours, 3) } 2-3 \text { hours, 4) }>3 \text { hours }\end{array}$ \\
\hline $\begin{array}{l}\text { Compulsive } \\
\text { internet use [22] }\end{array}$ & $\begin{array}{l}\text { Compulsive Internet Use Scale (CIUS) E.g. Do you rather spend time } \\
\text { on the internet than spending time with others? (total: } 14 \text { items) }\end{array}$ & $\begin{array}{l}\text { 0) Never, 1) Rarely, 2) Sometimes, 3) Often, 4) } \\
\text { Very often }\end{array}$ \\
\hline $\begin{array}{l}\text { Compulsive } \\
\text { videogame } \\
\text { playing [21] }\end{array}$ & $\begin{array}{l}\text { Videogame Addiction Test (VAT). E.g. Do you rather spend time playing } \\
\text { videogames than spending time with others? (total: } 14 \text { items) }\end{array}$ & $\begin{array}{l}\text { 0) Never, 1) Rarely, 2) Sometimes, 3) Often, 4) } \\
\text { Very often }\end{array}$ \\
\hline \multirow{2}{*}{$\begin{array}{l}\text { Body Mass } \\
\text { Index [32] }\end{array}$} & How tall are you (no shoes)? & Number of $\mathrm{cm}$ \\
\hline & What do you weigh? & Number of kg \\
\hline $\begin{array}{l}\text { Psychosocial } \\
\text { problems [38] }\end{array}$ & $\begin{array}{l}\text { Strengths and Difficulties Questionnaire (SDQ) E.g. I am easily } \\
\text { distracted, I find it difficult to focus (total: } 20 \text { items) }\end{array}$ & 0) Not true, 1) A little true, 2) Very true \\
\hline $\begin{array}{l}\text { General } \\
\text { Self-Efficacy [43] }\end{array}$ & $\begin{array}{l}\text { General Self-Efficacy (GSE) Survey. E.g. If you are going to do } \\
\text { something, are you afraid you will fail? (total: } 11 \text { items) }\end{array}$ & 0) Never, 1) Sometimes, 2) Often, 3) Very often \\
\hline
\end{tabular}


The items that differed from the HBSC questionnaire format are discussed in more detail below.

\section{Bullying}

The measurement of bully behavior was based on the Olweus Bully Score and the Olweus Bully Victim Score [37]. These scores distinguish bullies and bullied children from non-bullies and non-bullied children with a cut-off of " 2 to 3 times a month". These measures' validity and reliability were demonstrated in previous research, stating that these scores allow for prevalence estimates of bullying and being bullied to be obtained conveniently, that they have a reasonably well-defined meaning and that they are easily and unambiguously understood by users and researchers [34].

\section{Physical exercise and nutrition}

Healthy physical exercise was defined as at least one hour of moderately intensive physical exercise every day, where at least twice a week the activity is aimed at improving or maintaining physical fitness. Healthy eating habits were defined as a composite score of having breakfast, eating fruits and vegetables, all at least five times per week. Both are commonly used measures in The Netherlands and the Dutch HBSC [32].

\section{Screen time: watching television, internet use and videogame playing}

Internet use was defined as use of the computer/internet for non-school-related purposes. Videogame playing was defined as (online) gaming on a game console. Spending more than two hours/day on a screen time behavior was defined as "excessive" use [22]. The compulsiveness of someone's screen time behavior was measured by the Compulsive Internet Use Scale (CIUS) for compulsive internet use [22] and by the Videogame Addiction Test (VAT) for compulsive videogame playing [21]. The CIUS and VAT both represent a measurement of the core elements of compulsive or addictive behavior that are applicable to Internet use (e.g. loss of control, withdrawal symptoms, coping) [22]. These measures focus particularly on the compulsive and impulse control elements of Internet use and video game playing. To illustrate, issues such as whether one finds it difficult to stop using the Internet/playing video games, whether one rushes through homework to get to using the Internet/ video games or whether others say one should spend less time on the Internet/playing video games are questioned by both surveys $[21,22]$. Both the VAT and CIUS consist of 14 questions with a five-point Likert scale, used to evaluate compulsive behavior, respectively for compulsive videogame playing (CVP) and compulsive internet use (CIU). A mean score higher than 3.0 points indicates compulsive behavior.

\section{Health outcomes}

Three health-related indicators were measured. Firstly, psychosocial problems, which were measured by use of the Strengths and Difficulties Questionnaire (SDQ). This validated questionnaire measures emotional problems, conduct problems, hyperactivity, peer problems, and pro-social behavior, each composed of 5 items scored on a 3-point Likert-scale $(0=$ "not true", $1=$ "somewhat true" or 2 = "certainly true"). Together, except for the pro-social score, they add up to a total SDQ-score of maximum 40 points [38,39]. A score of 15 of higher is defined as "(potentially) problematic". The self-report SDQ's reliability and validity to measure the described psychosocial problem behaviors were recently demonstrated in a comparable sample of Dutch youth [40]. Van Widenfelt, Goedman, Treffers and Goodman later also stated that both the parent and self-report version of the SDQ are acceptable in terms of internal consistency, inter-informant correlations when compared to the "standards", i.e. the Child Behavior Checklist (CBCL) and the Youth Self Report survey (YSR) [41].

Secondly, "being overweight" was used to indicate unhealthy weight, based on the BMI corrected for age and gender, with appropriate cut-offs in adolescents [42]. Thirdly, due to the importance of self-esteem, social anxiety and assertiveness in adolescent development and psychosocial functioning, a composite measure of these concepts was integrated, which in the literature is referred to as "general self-efficacy" (GSE) [35]. Schwarzer's conceptual definition of GSE is applied here and that refers to the concept of how one describes his/her beliefs in their capabilities to practice control over challenging demands and regarding their functioning across these domains [43]. The operationalization of GSE measurement that was used was designed for use in Dutch adolescents [43] and based on Rosenberg's Self Esteem Scale [44] and Schwarzer's Generalized Self-Efficacy Scale [43]. The GSE questionnaire consisted of 11 questions with a 4-point Likert Scale, a higher score being indicative of more problems. The appropriate cut-off score of higher than 2.50 was used to indicate a problematic score [43].

\section{Statistical analyses}

All statistical analyses were performed with SPSS v20. First, Principal Component Analysis (PCA) was used to identify underlying behavioral patterns from the described health behaviors. Varimax rotation was used. Using the Varimax rotation method minimizes the number of variables that have high loadings on each factor and, as such, simplifies the interpretation of the factors. The extraction of factors in the analysis was based on the Scree Test, a factor loading of at least 0.30 after rotation based on sample size and number of tested variables 
[36,45] and conceptual meaningfulness [45]. In a followup analysis the number of factors to extract was assessed by parallel analysis [46], which compares Eigenvalues of factors from real data with factors from random data. Furthermore, two criteria were tested: the Kaiser-MeyerOlkin Measure of Adequacy (KMO), a measure of sampling adequacy (threshold: $\mathrm{KMO}>0.60$ ) and Bartlett's test of sphericity, which is used to test the null hypothesis that the variables in the population correlation matrix are uncorrelated (threshold: $\mathrm{p}<0.05$ ). This PCA produced standardized "component scores" via regression techniques.

Subsequently, a Two Step Cluster Analysis (TCA) was used to identify groups of adolescents with similar behavior and health outcomes [36]. The behavioral patterns (i.e. the component scores derived from the PCA) were used as input variables in the TCA, together with the socio-demographics age, gender, school level, ethnicity, socio-economic status and health outcomes (being overweight, GSE problems and psychosocial problems) [36,45]. A Two-Step Cluster Analysis is used here, due to the mixture of categorical and continuous variables. As stated by Norušis, other cluster analysis approaches will not suffice, since they rely on either continuous or categorical data (hierarchical clustering) or on a preset number of clusters to be distilled (K-means cluster analysis), whereas the TCA can perform an exploratory cluster analysis using a combination of different types of variables [47].

\section{Results}

A total of 2,690 adolescents (response rate 79.8\%) aged 11-18 years completed the survey. Students' characteristics are listed in Table 2. Approximately $45 \%$ were boys and the students' average age was 14 years. Approximately $73 \%$ of the 2690 students were native Dutch students; the rest of the students were mostly part of the major ethnic sub-populations of people originating from Morocco, Surinam, Turkey and the former Dutch Antilles.

\section{Principal component analysis}

The sample was considered suitable for factor analysis [36,45], as both the KMO measure (0.69) and Bartlett test of sphericity $(\mathrm{p}<0.001)$ exceeded the pre-set threshold. Results of the Principal Component Analysis (PCA) indicated that several separate distinct behavioral patterns (the "components" deduced from the PCA) underlie the individual behaviors. From the Scree Plot and further analysis four different behavioral patterns were deduced $[36,45]$. Selecting more or less than four factors was not in accordance with both the Scree Plot and Parallel Analysis [46], and left a non-interpretable factor solution. The four factors together explained approximately $55 \%$ of the total variance of the fourteen analyzed items. Further details of the PCA (item patterns, factor loadings and explained
Table 2 Student Characteristics $(\mathrm{N}=\mathbf{2 , 6 9 0 )}$

\begin{tabular}{|c|c|}
\hline & N (\%) \\
\hline \multicolumn{2}{|l|}{ Age in years } \\
\hline $11-12$ & $648(24.1)$ \\
\hline $13-14$ & $1300(48.4)$ \\
\hline $15-16$ & $639(23.8)$ \\
\hline $17-18$ & $102(3.8)$ \\
\hline Mean age in years & 13.68 (SD 1.45) \\
\hline Socio-economic status (FAS ${ }^{\mathrm{a}}$ score) & 7.13 (SD 1.49) \\
\hline Low (0-2) - Medium (3-5) & $393(14.6)$ \\
\hline High (6-9) & $2297(85.4)$ \\
\hline Watching TV (>14 h/week) & $549(21.0)$ \\
\hline Internet use (>14/week) & $730(27.1)$ \\
\hline Videogame playing (>14/week) & $186(6.9)$ \\
\hline Compulsive Internet Use, CIU & $94(3.5)$ \\
\hline Compulsive Videogame Playing, CVPc & $108(4.0)$ \\
\hline Being bullied & $124(4.7)$ \\
\hline Bullying & $77(2.9)$ \\
\hline Alcohol user & $702(26.1)$ \\
\hline Binge drinker & $477(19.6)$ \\
\hline Marihuana user & $170(6.3)$ \\
\hline Smoker & $231(8.6)$ \\
\hline Sufficing to Dutch Norm Healthy Physical Exercise ${ }^{d}$ & $1974(73.6)$ \\
\hline Sufficing to Dutch Norm Healthy Nutrition ${ }^{e}$ & $1186(44.1)$ \\
\hline \multicolumn{2}{|c|}{$\begin{array}{l}\text { a:FAS = Family Affluence Scale; }{ }^{b}: \text { CIU }=\text { Compulsive Internet Use Scale Score } \\
>3.0 \text { (range 0-4); }: \text { CVP = Videogame Addiction Test Score }>3.0 \text { (range } 0-4) ; \\
d^{d}: \text { Dutch Norm Healthy Physical Exercise: at least one hour of moderately } \\
\text { intensive physical exercise every day, where at least twice a week the activity } \\
\text { is aimed at improving or maintaining physical fitness; }{ }^{e} \text { :Dutch Norm Healthy } \\
\text { Nutrition: at least having breakfast, eating fruits and vegetables } 5 \text { times } \\
\text { per week. }\end{array}$} \\
\hline
\end{tabular}

variance) are presented in Table 3. Only the items with a factor loading of at least 0.30 are presented in Table 3 . From the PCA four main components were distilled, mainly indicating:

1 Risk-prone behavior (smoking, drug use, alcohol use and sexual activity).

2 Bully behavior (bullying \& being bullied and compulsive Internet use).

3 Problematic screen time use (weekly time and compulsiveness of playing videogames \& using the Internet).

4 Sedentary behavior (weekly time watching TV and using the Internet), unhealthy nutrition \& insufficient physical exercise.

The first factor consisted of the high-risk behaviors alcohol use, drug use, and smoking, and was thus termed risk-prone behavior. The second factor consisted 
Table 3 Factor structure of health behaviors in the study sample (only loadings of above 0.30 presented)

\begin{tabular}{|c|c|c|c|c|}
\hline $\begin{array}{l}\text { Behavioral } \\
\text { components }\end{array}$ & $\begin{array}{l}\text { Factor 1: Risk-prone } \\
\text { behavior }\end{array}$ & $\begin{array}{l}\text { Factor 2: Bully } \\
\text { behavior }\end{array}$ & $\begin{array}{l}\text { Factor 3: Problematic } \\
\text { screen time use }\end{array}$ & $\begin{array}{l}\text { Factor 4: Sedentary } \\
\text { behavior }\end{array}$ \\
\hline Smoking & .66 & & & \\
\hline Cannabis use & .73 & & & \\
\hline Binge drinking & .78 & & & \\
\hline Quantity of alcohol use & .80 & & & \\
\hline Having had intercourse & .65 & & & \\
\hline Healthy nutrition & & & & -.50 \\
\hline Healthy physical exercise & & & & -.65 \\
\hline Excessively watching TV & & & .32 & .57 \\
\hline Excessive PC/internet use & & & .32 & .65 \\
\hline Excessively playing videogames & & & .80 & \\
\hline Compulsive PC/internet use & & .32 & .54 & \\
\hline Compulsive videogame playing & & & .85 & \\
\hline Being a bully victim & & .82 & & \\
\hline Being a bully & & .86 & & \\
\hline Eigenvalue & 2.938 & 2.252 & 1.423 & 1.091 \\
\hline Variance explained \% & 19.132 & 13.725 & 11.216 & 10.959 \\
\hline Cumulative variance explained \% & 19.132 & 32.857 & 44.073 & 55.032 \\
\hline
\end{tabular}

$\mathrm{KMO}$ measure of sampling adequacy $=.69$ (based on Kaiser's criteria: $\mathrm{KMO} \geq .60$ means that the result of the factor analysis is acceptable). Bartlett's test of sphericity: $\mathrm{X} 2=6853.250(\mathrm{df}=91 ; \mathrm{p}<.000)$.

of bullying, being bullied and compulsive PC/Internet use, termed the bully behavior factor. Thirdly, the different aspects of screen time use (i.e. its compulsive component and its excessive use component) formed a separate factor. The fourth factor consisted of the components low physical activity, poor nutrition habits combined with excessively watching $\mathrm{TV}$ and using the PC/Internet. This particular aspect of screen time use was related to poor physical exercise and nutrition patterns, whereas the compulsiveness of screen time use had no correlation with those behaviors. This fourth factor was thus termed the sedentary behavior factor. Due to theoretical considerations, and because both loaded above 0.30 in the PCA, compulsive $\mathrm{PC} /$ Internet use was included in both factor 2 as well as in factor 3 and excessive PC/Internet use and excessively watching TV were also both included in two different factors (further elaboration upon these choices is presented in the Discussion).

\section{Two-step cluster analysis}

Four clusters were deducted from the Two-step Cluster Analysis (TCA), details are presented in Table 4. Cluster 1 presented the healthiest cluster with the most positive scores in terms of both health behaviors as well as health outcomes. These students were characterized by an average score with regard to sedentary behavior and a low score (i.e. healthy/positive score) on the other three behavioral pattern component scores. This "healthy cluster" was characterized by an average socio-economic status, a mix of different school levels, being of a native Dutch ethnicity and being girls.

Cluster 2 and 4 were also relatively healthy behaving students but differed in certain aspects from cluster 1. First, cluster 2 had a slightly higher socio-economic status than cluster 1 and consisted only of boys. Also, they presented unhealthier behavior than students of cluster 1 with regard to problematic screen time use (factor 3 ) and risk-prone behavior (factor 1, although they did not score above average on this factor). Cluster 2 also showed healthier behavior with regard to sedentary behavior (factor 4) compared to cluster 1. Furthermore, similar to cluster 1, cluster 2 was also characterized by positive scores on all three health outcomes.

Cluster 4 was similar to the other two "healthy" clusters in terms of scoring positive health outcomes and relatively healthy behavior in terms of risk-prone behavior (factor 1) and bully behavior (factor 2) as well as scoring average on sedentary behavior (factor 4). Typical for cluster 4 was that those students were of a nonDutch ethnicity, had a low socio-economic status, and consisted of a mix of boys and girls.

Finally, cluster 3 differed from all other clusters. Cluster 3 contained the unhealthiest scores on all four behavioral patterns, as well as the unhealthiest outcomes, namely a high BMI, a problematic SDQ and GSE score. This cluster comprised of students from all ethnicities, an average socio-economic status and school level and consisted of both boys and girls. 
Table 4 Clusters of health behaviors, health outcomes and demographics, formed by Two Step Cluster Analysis $(\mathrm{N}=\mathbf{2}, \mathbf{6 9 0})$

\begin{tabular}{|c|c|c|c|c|}
\hline & Cluster 1 & Cluster 2 & Cluster 3 & Cluster 4 \\
\hline & $35.6 \%$ & $26.4 \%$ & $19.8 \%$ & $18.3 \%$ \\
\hline \multicolumn{5}{|l|}{ Demographics characteristics } \\
\hline Gender & Girl (100\%) & Boys (100\%) & Mixed (58\% Girls) & Mixed (58\% Girls) \\
\hline Age & 13.6 years & 13.7 years & 14.0 years & 13.6 years \\
\hline SES (FAS score) ${ }^{1}$ & Normal to High (7.27) & High (7.50) & Normal (6.98) & Low (6.38) \\
\hline School level & Average / Mixed & Average / Mixed & Average / Mixed & Average / Mixed \\
\hline Ethnicity & Native Dutch (100\%) & Native Dutch (100\%) & Mixed (81\% Native Dutch) & Non- native Dutch (100\%) \\
\hline \multicolumn{5}{|l|}{ Health behaviors ${ }^{2,3}$} \\
\hline Factor 1: Risk-prone behavior & $\operatorname{Low}(-0.16)$ & Normal (0.09) & High (0.48) & $\operatorname{Low}(-0.24)$ \\
\hline Factor 2: Bully behavior & $\operatorname{Low}(-0.12)$ & $\operatorname{Low}(-0.20)$ & High (0.60) & $\operatorname{Low}(-0.19)$ \\
\hline Factor 3: Problematic screen time use & $\operatorname{Low}(-0.39)$ & High (0.26) & High (0.29) & Normal (0.02) \\
\hline Factor 4: Sedentary behavior & Normal (-0.06) & $\operatorname{Low}(-0.20)$ & High (0.18) & High (0.27) \\
\hline \multicolumn{5}{|l|}{ Health outcomes } \\
\hline Weight status & Normal BMI & Normal BMI & High BMI & Normal to High BMI \\
\hline Self-efficacy problems & Normal GSE (100\%) & Normal GSE (100\%) & Problematic GSE (32\%) & Normal GSE (100\%) \\
\hline Psychosocial problems & Normal SDQ (100\%) & Normal SDQ (100\%) & Problematic SDQ (71\%) & Normal SDQ (100\%) \\
\hline
\end{tabular}

${ }^{1}$ Indications of low, medium and high are indicative of a relatively low, medium or high socioeconomic status in this particular sample of adolescents.

${ }^{2} \mathrm{~A}$ low score on a lifestyle factor score indicates less exertion of such behavior.

${ }^{3}$ All Factors are standardized regression scores with a mean of 0 and a standard deviation of 1.

\section{Discussion}

This study aimed to identify clustering of a comprehensive number of health-related behaviors in adolescents, and to identify groups of adolescents with similar behavior and health outcomes. Four distinct behavioral patterns were found, namely 1 ) risk-prone behavior, consisting of high/unhealthy scores with regard to smoking, alcohol use, drug use and being sexually active, 2) bully behavior, consisting of significant factor loadings from the variables of bullying, being bullied and compulsive internet use, 3) problematic screen time behavior, meaning a high/unhealthy score regarding compulsive and excessive screen time use, and 4) sedentary behavior, i.e. excessive screen time use combined with poor physical exercise and nutritional habits.

After integrating these behavioral patterns together with several demographic factors and health-related outcomes, four clusters of adolescents were distinguished. One cluster was dominantly the healthy cluster, in which all behavioral pattern scores were all relatively most healthy as well as their situation on account of the healthrelated outcomes. These students were native Dutch girls from a mix of different socio-economic statuses and school levels. Two other clusters (cluster 2 and 4) differed only slightly from the healthy cluster. Cluster 2 included native Dutch boys, with unhealthy scores on the problematic screen time behavior factor, and average instead of low scores on the risk-prone behavior factor. They also showed positive health-related outcomes. Cluster 4 consisted only of adolescents of non-Dutch ethnicity, mostly with a low socio-economic status, and consisting of a mix of boys and girls. The only behavior pattern in which they scored poorly (i.e. unhealthy) was sedentary behavior (factor 4). Being overweight was also a characteristic of this cluster. Cluster 3 showed strong clustering of both negative health-related outcomes and unhealthy scores on all behavioral patterns, independent of demographic factors.

\section{Behavioral factors}

Smoking, alcohol use, drug use and sex

The first deduced distinct behavioral pattern that was the risk-prone behavior factor. The individual behaviors that made up this factor (or pattern) were marihuana use, smoking, alcohol use and sexual activity. Of all studied behaviors these four all seem to present a normdeviating behavior and therefore the factor was named risk-prone behavior. Their correlation is in accordance with previous research, which has mostly focused on these behaviors out of all those that were studied in the current research. Van Nieuwenhuizen et al. for example also showed a strong correlation of substance use related behaviors and sexual behavior with factor analysis techniques, yet due to the different scope of included behaviors these results were only partly comparable to those of the current study [12]. No major differences in behavioral patterns from the study of Van Nieuwenhuizen or other previous studies were found $[9,12-15,49]$. 


\section{Bully behavior}

Secondly, being bullied and being a perpetrator of bullying formed a behavioral component in the PCA. Compulsive Internet use also loaded significantly on this factor. Despite the fact that this behavior loaded stronger on another factor (namely on factor 3), it was included in this bully behavior factor also, due to theoretical considerations, since previous research also reported on the relationship between the internet use of adolescents and their bully behavior [50]. Compulsive screen time use, when being bullied, could possibly indicate a kind of 'flight behavior' to a relative anonymous online environment in which one would feel safer. Thus, in this context compulsive screen time use seems to be part of a distinctly different overarching behavior than in factor 3 (discussed below). Therefore, it was included in two different factors, as is common practice in factor analyses when theoretical considerations are taken into account instead of merely looking at statistical considerations [36]. However, it has to be taken into consideration that such a theory is relative speculation due to the few comparable other studies on the topic.

Furthermore, the subsequent TCA confirmed their relationship to General Self-Efficacy and psychosocial problems. Students that scored worst on, among other unhealthy behavioral scores, bullying/being bullied also reported the worst psychosocial and GSE outcomes.

\section{Excessive versus compulsive screen time}

In the current study screen time behavior consisted of two aspects, namely excessive and compulsive screen time behaviors. Although these showed to be strongly inter-related (forming a separate behavioral pattern, i.e. factor 3) the associations of excessive and compulsive screen time behaviors to problematic health-related outcomes differed. Excessive screen time was significantly related to being overweight (Cluster 4, Table 3), while compulsive screen time was significantly more prevalent among students that also indicated psychosocial problems, problems with GSE and behaviors such as bullying/being bullied (behavioral factor 2) and risk-prone behaviors (behavioral factor 1) (Table 3). The findings related to excessive screen time behavior were in accordance with previous studies $[18,31,48,51]$. However, similar clustering studies that integrated the compulsive aspect of these behaviors in adolescents were not retrieved, although previous research has shown that, separately, compulsive and excessive screen time behaviors differ in their relation to outcomes such as psychosocial problems [52], educational outcomes [53] or physical health indicators [23]. Therefore, based on these theoretical considerations, compulsive and excessive screen time behaviors were included in more than one behavioral factor (Table 2).

\section{Screen time, physical exercise and eating habits}

The fourth behavioral pattern was the so-called sedentary behavior factor. Scoring high on this factor meant that students reported more excessive screen time use as well as low levels of physical exercise and unhealthy nutrition habits. Previous studies showed this clustering of nutrition and exercise $[11,14,17,18]$, but relatively few also integrated screen time use. Studies that did, showed relatively similar cluster patterns $[16,27,51]$. The current study shows that the more hours teens spend on watching television, using the internet and playing videogames, the less time they spend on physical exercise and the poorer they eat. Thus, for public health practice this would mean that solely focusing on e.g. weight reduction via attention for more sports participation and healthier nutrition seems inadequate. The screen time behavior of the children and adolescents of our digital age seems an inescapable phenomenon that has to be integrated in health promotion practices.

\section{Clustering of health behavior with health outcomes and demographic factors}

After deducing the overarching factors/behaviors from the individual behaviors, several noteworthy results were found in the subsequent TCA. Firstly, as predicted by previous studies expected from the literature, being overweight was significantly related to a lower socioeconomic status and behavioral factor 4 (sedentary behavior). Poorer scores on this behavioral pattern was one of the few aspects in which clusters 2 and 4 differed from one another, together with non-Dutch ethnicity and the higher correlation to being overweight of cluster 4 .

Secondly, the TCA revealed that poor scores on multiple behavioral patterns and poor health outcomes clustered within the same students. This was in accordance with previous comparable studies that showed that more problematic behaviors led to, or were associated with, poorer health outcomes $[3,4,8,13,17]$. Also, the clustering of compulsive screen time and bully behavior with psychosocial problems and low GSE is in line with other literature [54-56].

Furthermore, boys seem to exert unhealthier behavior than girls in comparable groups when reviewing cluster 1 versus cluster 2, especially with regard to risk-prone behavior and problematic screen time use. This is in line with the theory and findings of the meta-analysis of Byrnes, Miller and Schafer of over 150 studies on the subject that revealed a higher prevalence of risky behavior among males than females [57].

Finally, the clustering of health-related behaviors and outcomes showed to be independent of demographic factors socio-economic status, gender, ethnicity and school level. This is a finding that would indicate that unhealthy behavior is the main indicator for subsequent poor health- 
related outcomes and that demographic factors have only a minor influence on this. This is not in accordance with several previous studies that indicated a significant effect of, especially, socio-economic status. It was difficult to assess whether the lack of clustering with socio-economic status in the current study could be specific to the study sample, due to the relatively minor variations in socioeconomic status among Dutch adolescents in comparison to those in other countries.

\section{Strengths and weaknesses}

A strength of the current study was that we took into account a broad range of health-related behaviors that were previously not examined simultaneously in such a way. Many previous studies focused on subsets of these behaviors. Also, the use of validated questionnaires is an important strength of this study. Last, the response rate of $79.8 \%$ was a respectable one. The fact that certain students did not fill out the questionnaire was mostly attributable to teachers not presenting the questionnaire to their class; the indicated reasons for this were interfering schedules or that it was forgotten by the teacher. Therefore, non-response bias can be assumed to be minimal.

A limitation is the lack of integrating a multilevel structure in the factor and cluster analyses. For more optimal estimates a multilevel approach is preferred, although such approaches are still in their infancy [58]. However, given the strong factor loadings and strong effects that were found, it is highly unlikely that the impact of integrating a multilevel structure would have significantly changed them. Such effects are especially to be expected and relevant when the variables that are dealt with are cross-level latent constructs [58-60]. This means that if one were to measure higher level constructs (e.g. school climate) via individual level measurements, a multilevel approach would be more likely to be beneficial. However, this was not the case in the current study and therefore such approaches were less relevant. A second limitation of the current study is its crosssectional design, which inhibits establishing any causal relations. Also, this study used a sample of young adolescents from the Netherlands, which is no guarantee for generalization to other countries. Especially the relatively limited variation with respect to socio-economic might limit the possibility for generalization of some results.

\section{Conclusions}

The results show that health-related behaviors tend to cluster, indicating that specific behavioral patterns underlie individual health behaviors. This resulted in the deduction of four distinct behavioral patterns, namely 1) Riskpronebehavior (alcohol and drug use, smoking and early sexual activity), 2) Bully behavior (bullying, being bullied and compulsive Internet use), 3) Problematic screen time use (excessively watching television and compulsively and excessively playing video games and using the Internet), and 4) Sedentary behavior (low physical exercise, poor nutritional habits and excessively watching television, playing videogames and using the Internet). Subsequently, four clusters of adolescents were identified; multi-problem behavior was associated with problematic physical and psychosocial health outcomes, as opposed to those exerting relatively few unhealthy behaviors. These associations were relatively independent of demographics such as ethnicity, gender and socio-economic status. Overall, this study adds to the current knowledge on how health behaviors cluster within individuals and that certain combinations of behaviors can be used to target high-risk individuals, which were shown to be of significantly higher risk of poorer physical and psychosocial health outcomes.

Additionally, the findings of this study have significant implications for future school-based prevention programs. As Wiefferink et al. suggested, such knowledge on health behavioral clustering can be used to design more effective and feasible school based interventions using Transfer-oriented Learning [61]. Transfer-oriented Learning is said to take place when students apply independently and flexibly what they have learned in a context different to that in which they learned it [61]. This means for example that, if resisting peer pressure would be an important tool to prevent youth from starting smoking, such a skill can also be learnt to be applied in a different context, e.g. when teaching students to resist drug use or to partake in unprotected sex; certain common determinants can be transferred to teachings on different topics. Although a specific behavioral context is still needed to teach knowledge, attitudes and skills, Transfer-oriented Learning does facilitate more feasible school based interventions, because topics can be integrated, which lightens the load on the curriculum. Also, it would increase the outreach that school based interventions could have when multiple behaviors are targeted simultaneously. Given these developments, it is a positive development to see school based interventions move towards a comprehensive, whole school approach that would facilitate a clustered approach to improving health behaviors among children and adolescents [29]. To improve upon current practices in this area, research on the clustering of health behaviors is vital, since it is necessary to identify common determinants across different types of health behaviors. This study therefore adds significantly to the current knowledge.

\section{Competing interests}

The authors declare that they have no competing interests.

\section{Authors' contributions}

VB and HVS designed the study, performed the data analysis, and wrote the first draft of the article. VB and RDL collected all data. All authors participated in the interpretation of the findings and finalizing the paper. All authors 
revised and approved the final draft. GS is responsible for study supervision. All authors share equal responsibility for the paper and approve the final manuscript.

Received: 4 March 2013 Accepted: 29 November 2013

Published: 4 December 2013

\section{References}

1. Kemper HCG, Snel J, Verschuur R, Storm-Van Essen L: Tracking of health and risk indicators of cardiovascular diseases from teenager to adult: Amsterdam growth and health study. Prev Med 1990, 19:642-655.

2. World Health Organization: 2008-2013 Action Plan for the Global Strategy for the Prevention and Control of Noncommunicable Diseases, Report Number 978924159741 8. Geneva, Switzerland: World Health Organization; 2011.

3. Pronk NP, Anderson LH, Crain AL, Martinson BC, O'Connor PJ, Sherwood NE, Whitebird RR: Meeting recommendations for multiple healthy lifestyle factors: prevalence, clustering, and predictors among adolescent, adult, and senior health plan members. Am J Prev Med 2004, 27:25-33.

4. Pronk NP, Peek CJ, Goldstein MG: Addressing multiple behavioral risk factors in primary care: a synthesis of current knowledge and stakeholder dialogue sessions. Am J Prev Med 2004, 27:4-17.

5. Longshore D, Ghosh-Dastidar B, Ellickson PL: National youth anti-drug media campaign and school-based drug prevention: evidence for a synergistic effect in ALERT plus. Addict Behav 2006, 31:496-508.

6. Werch C, Moore M, DiClemente C, Bledsoe R, Jobli E: A multihealth behavior intervention integrating physical activity and substance use prevention for adolescents. Prev Sci 2005, 6:213-226.

7. De Bruijn G, Van Den Putte B: Adolescent soft drink consumption, television viewing and habit strength. Investigating clustering effects in the theory of planned behavior. Appetite 2009, 53:66-75.

8. Plotnikoff RC, Karunamuni N, Spence JC, Storey K, Forbes L, Raine K, Cameron Wild T, McCargar L: Chronic disease-related lifestyle risk factors in a sample of Canadian adolescents. J Adolesc Health 2009, 44:606-609.

9. Huang DYC, Lanza HI, Murphy DA, Hser Yl: Parallel development of risk behaviors in adolescence: potential pathways to co-occurrence. Int J Behav Dev 2012, 36:247-257.

10. Prochaska JJ, Spring B, Nigg CR: Multiple health behavior change research: an introduction and overview. Prev Med 2008, 46:181-188.

11. Burke V, Milligan RAK, Beilin LJ, Dunbar D, Spencer M, Balde E, Gracey MP: Clustering of health-related behaviors among 18-year-Old Australians. Prev Med 1997, 26:724-733.

12. van Nieuwenhuijzen $M$, Junger $M$, Velderman MK, Wiefferink KH, Paulussen TWGM, Hox J, et al: Clustering of health-compromising behavior and delinquency in adolescents and adults in the Dutch population. Prev Med 2009, 48:572-578.

13. Hair EC, Park MJ, Ling TJ, Moore KA: Risky behaviors in late adolescence: co-occurrence, predictors, and consequences. J Adolesc Health 2009, 45:253-261.

14. Dumith SC, Muniz LC, Tassitano RM, Hallal PC, Menezes AMB: Clustering of risk factors for chronic diseases among adolescents from Southern Brazil. Prev Med 2012, 54:393-396.

15. Kulbok PA, Cox CL: Dimensions of adolescent health behavior. J AdolesC Health 2002, 31:394-400

16. Ottevaere C, Huybrechts I, Benser J, De Bourdeaudhuij I, Cuenca-Garcia M, Dallongeville J, et al: Clustering patterns of physical activity, sedentary and dietary behavior among European adolescents: the HELENA study. BMC Public Health 2011, 11:328.

17. Hardy LL, Grunseit A, Khambalia A, Bell C, Wolfenden L, Milat AJ: Co-occurrence of obesogenic risk factors among adolescents. J Adolesc Health 2012, 51:265-271.

18. Sanchez A, Norman GJ, Sallis JF, Calfas KJ, Cella J, Patrick K: Patterns and correlates of physical activity and nutrition behaviors in adolescents. Am J Prev Med 2007, 32:124-130.

19. Christakis D: Internet addiction: a 21st century epidemic? BMC Med 2010, 8:61.

20. Gentile DA, Lynch PJ, Linder JR, Walsh DA: The effects of violent video game habits on adolescent aggressive attitudes and behaviors. J Adolesc 2004, 27:5-22.

21. van Rooij AJ, Schoenmakers TM, Vermulst AA, van den Eijnden RJ, van de Mheen D: Online video game addiction: identification of addicted adolescent gamers. Addiction 2011, 106:205-212.
22. Meerkerk GJ, van den Eijden RJ, Vermulst AA, Garretsen HF: The compulsive internet Use scale (CIUS): some psychometric properties. CyberPsych Behav 2009, 12:1-6.

23. Tremblay MS, LeBlanc AG, Kho ME, Saunders TJ, Larouche R, Colley RC, Goldfield G, Connor Gorber S: Systematic review of sedentary behavio and health indicators in school-aged children and youth. Int J Behav Nutr Phys Act 2011, 8:98.

24. Nansel TR, Overpeck M, Pilla RS, Ruan WJ, Simons-Morton B, Scheidt P. Bullying behaviors among US youth: prevalence and association with psychosocial adjustment. JAMA 2001, 285:2094-2100.

25. Gini G, Pozzoli T: Association between bullying and psychosomatic problems: a meta-analysis. Pediatrics 2009, 123:1059-1065.

26. Esbensen FA, Carson DC: Consequences of being bullied: results from a longitudinal assessment of bullying victimization in a multisite sample of American students. Youth Soc 2009, 41:209-233.

27. Yen JY, Ko CH, Yen CF, Wu HY, Yang MJ: The comorbid psychiatric symptoms of internet addiction: attention deficit and hyperactivity disorder (ADHD), depression, social phobia, and hostility. J Adolesc Health 2007, 41:93-98.

28. Young KS: Internet addiction: The emergence of a new clinical disorder. CyberPsych Behav 1998, 1:237-244.

29. Clift S, Bruun Jensen B: The Health Promoting School: International Advances in Theory, Evaluation and Practice. Copenhagen, Denmark: Danish University of Education Press; 2005

30. Denman S: Health promoting schools in England, a way forward in development. J Public Health 1999, 21:215-220.

31. Yen LL, Chiu CJ, Wu WC, Pan LY: Aggregation of health behaviors among fourth graders in Northern Taiwan. J Adolesc Health 2006, 39:435-442.

32. Van Dorsselaer S, De Looze M, Vermeulen-Smit E, de Roos SVJ, ter Bogt T, Vollebergh W: Health, Well-Being and Education of Dutch Adolescents, HBSC 2009. Utrecht: Trimbos Instituut; Universiteit Utrecht; Sociaal en Cultureel Planbureau; 2010.

33. Currie C (Ed.): Health Behavior in School-Aged Children A WHO Cross-National Survey (HBSC) Research Protocol for the 1997-98 survey. Edinburgh: Research Unit in Health and Behavioral Change, University of Edinburgh; 1998.

34. Kyriakides L, Kaloyirou C, Lindsay G: An analysis of the revised olweus bully/victim questionnaire using the rasch measurement model. Br J Educ Psychol 2006, 76:781-801.

35. Bandura A: Self-efficacy: toward a unifying theory of behavior change. Psychol Rev 1977, 84:191-215.

36. Field A: Discovering Statistics Using SPSS. 3rd edition. Thousand Oaks: SAGE Publications Itd; 2009.

37. Solberg ME, Olweus D: Prevalence estimation of school bullying with the olweus bully/victim questionnaire. Aggr Behav 2003, 29:239-268.

38. Goodman R: The strengths and difficulties questionnaire: a research note. J Child Psychol Psychiatry 1997, 38:581-586.

39. Goodman R, Meltzer H, Bailey V: The strengths and difficulties questionnaire: a pilot study on the validity of the self-report version. Eur Child Adolesc Psychiatry 1998, 7:125-130.

40. Muris $P$, Meesters $C$, van den Berg F: The strengths and difficulties questionnaire (SDQ): further evidence for its reliability and validity in a community sample of Dutch children and adolescents. Eur Child Adolesc Psychiatry 2003, 12:1-8

41. Van Widenfelt BM, Goedhart AW, Treffers PDA, Goodman R: Dutch version of the strengths and difficulties questionnaire (SDQ). Eur Child Adolesc Psychiatry 2003, 12:281-289.

42. Cole TJ, Bellizzi MC, Flegal KM, Dietz WH: Establishing a standard definition for child overweight and obesity worldwide: international survey. $B M$ 2000, 320:1240-1243.

43. Teeuw B, Schwarzer $R$, Jeruzalem M: Dutch adaptation of the general self-efficacy scale. 1994. http://userpage.fu-berlin.de/ health/dutch.htm

44. Rosenberg M: Society and the Adolescent Self-Image. Princeton, NJ, United States: Princeton University Press; 1972.

45. Stevens JP: Applied Multivariate Statistics for the Social Sciences. 5th edition. New York: Taylor \& Francis; 2012.

46. Garson DG: Factor Analysis, Statistical Associates Blue Book Series, Statistical Associates Publishing. School of Public \& International Affairs. Asheboro, NC, USA: North Carolina State University; 2013

47. Norušis MJ: Cluster Analysis. In PASW Statistics 18 Statistical Procedures Comparison. Upper Saddle River, NJ: Prentice-Hall; 2010. 
48. Haerens L, Deforche B, Maes L, Cardon G, Stevens V, De Bourdeaudhuij I: Evaluation of a 2-year physical activity and healthy eating intervention in middle school children. Health Educ Res 2006, 21:911-921.

49. Mistry R, McCarthy WJ, Yancey AK, Lu Y, Patel M: Resilience and patterns of health risk behaviors in California adolescents. Prev Med 2009, 48:291-297.

50. Norris TL: Adolescent Academic Achievement, Bullying Behavior, and the Frequency of Internet use. Ohio, United States: Kent State University; 2010.

51. Regan A, Heary C: Patterns of sedentary behaviors in Irish female adolescents. J Adolesc 2013. 36:269-278.

52. Busch V, Manders LA, de Leeuw JRJ: Screen time associated with health behaviors and outcomes in adolescents. Am J Health Behav 2013, 37:819-830.

53. Johnson JG, Cohen P, Kasen S, Brook JS: Extensive television viewing and the development of attention and learning difficulties during adolescence. Arch Pediatr Adolesc Med 2007, 161:480-486.

54. Caplan SE: Relations among loneliness, social anxiety, and problematic internet use. Cyberpsychol Behav 2007, 10:234-242.

55. Beran TN, Lupart J: The relationship between school achievement and peer harassment in Canadian adolescents the importance of mediating factors. Sch Psychol Int 2009, 30:75-91.

56. Fekkes M, Pijpers FIM, Fredriks AM, Vogels T, Verloove-Vanhorick SP: Do bullied children get ill, or do ill children get bullied? a prospective cohort study on the relationship between bullying and health-related symptoms. Pediatrics 2006, 117:1568-1574.

57. Byrnes JP, Miller DC, Schaffer WD: Gender differences in risk taking: a meta-analysis. Psychol Bull 1999, 125:367-383.

58. Marsh HW, Muthen B, Asparouhov T, Ludtke O, Robitzsch A, Morin AJS, Trautwein U: Exploratory structural equation modeling, integrating CFA and EFA: application to Students' evaluations of university teaching. Struct Equ Modeling 2009, 16:439-476.

59. Dyer NG, Hanges PJ, Hall RJ: Applying multilevel confirmatory factor analysis techniques to the study of leadership. Leadersh Q 2005, 16:149-167.

60. D'Haenens E, van Damme J, Oghena P: Multilevel exploratory factor analysis: illustrating its surplus value in educational effectiveness research. School Eff School Improv 2010, 21:209-235.

61. Wiefferink CH, Peters L, Hoekstra F, Dam GT, Buijs GJ, Paulussen TG: Clustering of health-related behaviors and their determinants: possible consequences for school health interventions. Prev Sci 2006, 7:127-149.

doi:10.1186/1471-2458-13-1118

Cite this article as: Busch et al:: Clustering of health-related behaviors, health outcomes and demographics in Dutch adolescents: a cross-sectional study. BMC Public Health 2013 13:1118.

\section{Submit your next manuscript to BioMed Central and take full advantage of:}

- Convenient online submission

- Thorough peer review

- No space constraints or color figure charges

- Immediate publication on acceptance

- Inclusion in PubMed, CAS, Scopus and Google Scholar

- Research which is freely available for redistribution 